\title{
Novel Pyran Derivative Ornamented with free Amino and Nitrile Functionalities: Synthesis and Spectroscopic Characterization
}

\author{
Chandran Udhaya Kumar, Ramar Sivaramakarthikeyan, Kannan Gokula Krishnan, Muthiah \\ Pillai Velayutham Pillai, Chennan Ramalingan
}

\begin{abstract}
A novel 4H-pyran derivative tethered with free amino and nitrile groups (1) was synthesized from commercially available meta-bromobenzaldehyde, malononitrile and 2-(methacryloyloxy)ethyl 3-oxobutanoate by adopting a one-step three components reaction strategy. The structure of the synthesized 1 has been established based on physical and spectroscopic methods such as infrared, one dimensional proton and carbon nuclear magnetic resonance as well as two-dimensional HSQC and HMBC spectral techniques.
\end{abstract}

Keywords: Pyran, MCR, Vibrations, HSQC, HMDC.

\section{INTRODUCTION}

Multi-component reactions (MCRs), occasionally also called as multi-component assembly processes (MCAPs) and an important sub-class of tandem reactions are nothing but chemical reactions performed with three or more components in a single-step wherein the resulting products must contain components from all the substrates utilized. In recent years, enormous interests have been exposed in the direction of the reactions under the category of multi-component in the domains of medicinal chemistry as well as organic synthesis [1-2]. A diverse range of advantages associated with these methodologies includes atom economy, structural diversity, eco-friendliness, high selectivity, solvent-free strategies, and good yields [3-5]. Specifically, synthesis of heterocyclic compounds utilizes multi-component reactions in larger ways

Revised Manuscript Received on December 17, 2019.

* Correspondence Author

Chandran Udhaya Kumar, Department of Chemistry, School of Advanced Sciences, Kalasalingam Academy of Research and Education (Deemed to be University), Krishnankoil, 626 126, Tamilnadu, India. Email: udhayaa.chem86@gmail.com

Ramar Sivaramakarthikeyan, Department of Chemistry, School of Advanced Sciences, Kalasalingam Academy of Research and Education (Deemed to be University), Krishnankoil, 626 126, Tamilnadu, India. Email: sivaram.ramar@gmail.com

Kannan Gokula Krishnan, Department of Chemistry, School of Advanced Sciences, Kalasalingam Academy of Research and Education (Deemed to be University), Krishnankoil, 626 126, Tamilnadu, India. Email: gokulakrishnank83@gmail.com

Muthiah Pillai Velayutham Pillai , Department of Chemistry, School of Advanced Sciences, Kalasalingam Academy of Research and Education (Deemed to be University), Krishnankoil, 626 126, Tamilnadu, India. Email: m.velayuthampillai@klu.ac.in

* Chennan Ramalingan, Department of Chemistry, School of Advanced Sciences, Kalasalingam Academy of Research and Education (Deemed to be University), Krishnankoil, 626 126, Tamilnadu, India. Email: ramalinganc@gmail.com
[6-8]. Subsequently, development of proficient and green reaction strategies which focus on target chemical entities is a vital noteworthy challenge in synthetic organic chemistry $[9,10]$.

Heterocyclic molecules resembling pyrans add functional variety to the chemical entity and offer prolific area to learn their bio-activity. It is recognized that chemical entities possessing $4 H$-pyran structural motif are one of the honored heterocyclic ones for the reason that many of their derivatives enjoy useful pharmacological profiles $[11,12]$ and a wide variety of biological properties, which include anticancer, anti-HIV, antimalarial, anti-inflammatory, antibacterial, antifungal, and antimalarial [13-18].

Owing to the importance with respect to biological profile, researchers around the globe have developed diverse strategies for the construction of pyran structural motif by utilizing various catalysts. A few of novel methods include three component reaction utilizing the catalysts such as piperidine, basic ionic liquid, $S$-proline, Nano-ZnO hydroxyapatite (HAP), and heteropoly acids [19-25]. Although various methodologies have been developed for the construction of pyran ring system, development of a better method with various advantages is highly desired.

In the present piece of research work, an exhaustive exploration results on the synthesis as well as structural characterization of a novel $4 \mathrm{H}$-pyran derivative tethered with free amino and nitrile groups (1) has been disclosed. The structure of the synthesized pyran molecule is established by physical as well as spectroscopic methods such as infrared, one dimensional proton and carbon nuclear magnetic resonance as well as two-dimensional HSQC and HMBC spectral techniques.

\section{EXPERIMENTAL SECTION}

\section{A. Materials and methodologies}

The solvents, starting materials, and reagents were obtained from commercial sources suppliers and utilized as such with no additional purification. Melting point was recorded in open air capillary and is uncorrected. Fourier transform infrared spectrum was measured on an Avatar Nicolet FT-IR spectrometer (frequency range between 4000 and $400 \mathrm{~cm}^{-1}$ ) for the title molecule in $\mathrm{KBr}$ pellets. 


\section{Novel Pyran Derivative Ornamented with free Amino and Nitrile Functionalities: Synthesis and Spectroscopic Characterization}

The proton and carbon nuclear magnetic spectra were acquired on a Bruker AMX400 spectrometer utilizing tetramethyl silane as the internal reference and $\mathrm{CDCl}_{3}$ as the solvent. The splitting patterns in the proton NMR are furnished as multiplet (m), doublet (d) and singlet (s).

\section{B. Synthesis of novel $4 \mathrm{H}$-pyran derivative 1}

In an RB flask with saturated potassium carbonate solution $(50 \mathrm{ml})$, methacryloyloxy substituted ketone $(1.0 \mathrm{mmol})$, 3-bromo benzaldehyde $(1.0 \mathrm{mmol})$ and malononitrile $(1.0$ mmol) were taken and it was stirred at $\sim 80^{\circ} \mathrm{C}$ for $7 \mathrm{~min}$. The thrown-out precipitate, after the addition of cold-water (100 $\mathrm{mL}$ ), was separated by filtration. The solid thus obtained was further washed well with a large quantity of water and eventually purified by recrystallization from ethanol:chloroform (3:1) to acquire the $4 H$-pyran derivative 1 in pure form. Yield $82 \%$, MP: $140-142{ }^{\circ} \mathrm{C}$. IR $\left(\mathrm{cm}^{-1}, \mathrm{KBr}\right.$,): 3391, 3314, 3195, 3192, 3187, 2993, 2964, 2924, 2195, 1722, 1689, 1607, 1564, 1454, 1404, 1378, 1375, 1325, 1303, 1128, 1070, 935, 883, 848, 729, 690, 675, 499, 478, 437. ${ }^{1} \mathrm{H}$ NMR (400 MHz, $\left.\mathrm{CDCl}_{3}, \mathrm{ppm}\right) \delta: 7.34-7.32(2 \mathrm{H}, \mathrm{d}$, Ar-H), 7.14-7.13 (2H, d, Ar-H), 6.05 (1H, s, H-16a), 5.60 $(1 \mathrm{H}, \mathrm{s}, \mathrm{H}-16 \mathrm{~b}), 4.70\left(2 \mathrm{H}, \mathrm{s}, \mathrm{NH}_{2}\right), 4.39(1 \mathrm{H}, \mathrm{s}, \mathrm{H}-4)$, 4.30-4.20 (4H, m, H-10 \& H-11), 2.39 (3H, s, H-18), 1.92 $(3 \mathrm{H}, \mathrm{s}, \mathrm{H}-17) .{ }^{13} \mathrm{C}$ NMR $(\delta): 167.0,165.3,158.2,157.7$, 146.1, 135.7, 130.5, 130.4, 130.2, 126.3, 122.8, 118.6, 107.0, $62.4,62.2,61.5,38.618 .7,18.3$.

\section{RESULTS AND DISCUSSION}

\section{A. Synthesis}

Synthesis of any molecule using water as a medium is the best one as for as synthetic chemistry is concerned. Initially, a mixture of 2-(methacryloyloxy)ethyl 3-oxobutanoate, 3-bromo benzaldehyde, and malononitrile were stirred in a solution of aqueous $\mathrm{K}_{2} \mathrm{CO}_{3}$ (saturated) at $\sim 80{ }^{\circ} \mathrm{C}$ for $7 \mathrm{~min}$. After standard workup and purification of the reaction mixture via recrystallization, the product $4 H$-pyran derivative 1 was obtained in $82 \%$ yield (Scheme 1). Complete characterization involving infrared, one dimensional proton and carbon nuclear magnetic resonance as well as two-dimensional HSQC (Heteronuclear Single Quantum Coherence) and HMBC (Heteronuclear Multiple Bond Correlation) spectral techniques proved the identity of novel $4 H$-pyran derivative 1 .

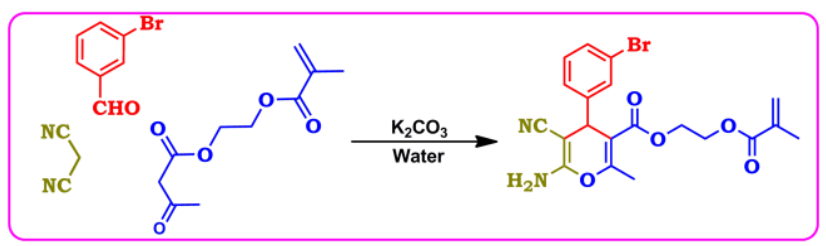

\section{Scheme 1 Synthesis of $4 \mathrm{H}$-pyran derivative 1}

\section{B. Infrared spectral analysis of novel 4H-pyran derivative 1}

The experimental infrared spectrum of $4 H$-pyran derivative $\mathbf{1}$ is displayed in Fig. $\mathbf{1}$ and the selected absorptions frequencies are presented in Table $\mathbf{1 .}$

\section{C-H Vibrations}

The vibrations (stretching) of carbon and hydrogen bond in the aromatic ring usually appear nearly from 3100 to 3000 $\mathrm{cm}^{-1}$ [26]. In the Fourier transform Infrared spectrum, the band resulted at $\sim 3100 \mathrm{~cm}^{-1}$ is due to stretching vibration of carbon and hydrogen in the aromatic unit of 4H-pyran derivative 1. The stretching vibrations of carbon and hydrogen in the aliphatic region are experimentally noted at 2993, 2964 and $2924 \mathrm{~cm}^{-1}$.

\section{D. $\mathbf{C}=\mathbf{O}$ Vibrations}

In the FT-IR spectrum, the carbonyl group with various environments generally appear as a strong band in the range between $1800-1600 \mathrm{~cm}^{-1}$ [26,27]. In the $4 H$-pyran derivative 1, the $\mathrm{C}=\mathrm{O}$ stretching vibrations of the carbonyl group connected to the carbon carrying olefinic functionality as well as methyl moiety and the other $\mathrm{C}=\mathrm{O}$ group attached to a carbon of pyran nucleus are resulted at 1749 and $1689 \mathrm{~cm}^{-1}$, respectively.

Table 1. Selected IR Absorptions of target molecule.

\begin{tabular}{lll}
\hline S.No. & IR frequency $\left(\mathbf{c m}^{-\mathbf{1}}\right)$ & Functional groups \\
\hline 1 & $3195,3192,3187$ & Ar. C-H (stretch) \\
2 & $2993,2964,2924$ & Ali. C-H (stretch) \\
3 & 2195 & $\mathrm{C} \equiv \mathrm{N}$ \\
3 & 1722 & $\begin{array}{l}\mathrm{C}=\mathrm{O} \text { connected to } \\
\text { olefinic carbon } \\
\end{array}$ \\
4 & 1689 & $\mathrm{C}=\mathrm{O}$ connected to \\
& & pyran ring \\
5 & 3391,3314 & $\mathrm{NH}$ \\
6 & 675 & $\mathrm{C}-\mathrm{Br}$ \\
\hline
\end{tabular}

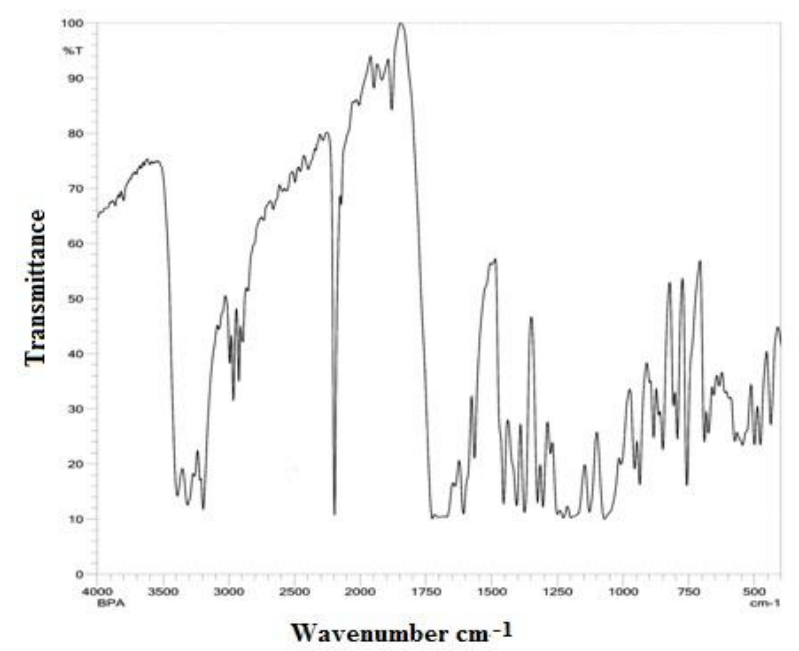

Fig. 1. IR spectrum of target molecule 1

\section{E. $\mathbf{C} \equiv \mathbf{N}$ Vibrations}

The nitrile groups normally provide unique spectral values and gives intense absorption between 2280 and $2200 \mathrm{~cm}^{-1}$. In the current investigation, the stretching vibration of $\mathrm{C} \equiv \mathrm{N}$ integrated at one of the carbons of pyran structural unit noted at $2195 \mathrm{~cm}^{-1}$ in the FT-IR spectrum (experimental). 


\section{F. $\mathbf{N H}_{2}$ Vibrations}

In a spectrum of FT-IR, the existence of a primary amino functionality normally shows stretching vibrations of N-H in the range between 3400 and $3300 \mathrm{~cm}^{-1}$. The FT-IR spectrum of $4 H$-pyran derivative $\mathbf{1}$ depicts two typical bands at 3391 and $3314 \mathrm{~cm}^{-1}$, confirming the presence of $\mathrm{NH}_{2}$.

\section{G. C-Br Vibrations}

In most of the bromoaryl molecules, the stretching vibrations of $\mathrm{C}-\mathrm{Br}$ present in the range between 650 and 395 $\mathrm{cm}^{-1}$ [27]. In the FT-IR spectrum, the characteristic band resulted at $675 \mathrm{~cm}^{-1}$ is corresponds to stretching vibrations of carbon - bromo bond.

\section{H. NMR spectral analysis}

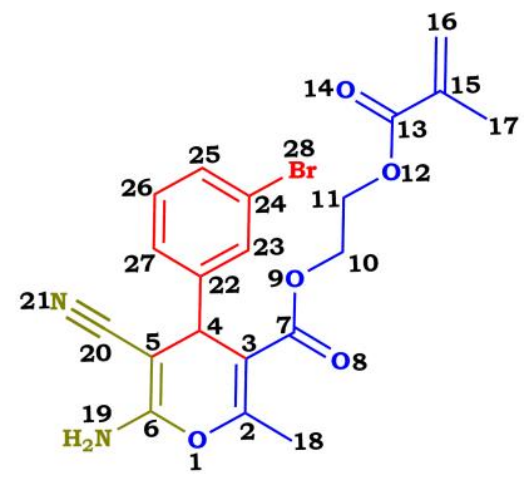

Structure of $4 H$-pyran derivative 1

\section{I. ${ }^{\mathbf{1}} \mathrm{H}$ NMR analysis of $\mathbf{4 H}$-pyran derivative $\mathbf{1}$}

The ${ }^{1} \mathrm{H}$ NMR spectrum of $4 H$-pyran derivative $\mathbf{1}$ is given in Fig. 2. Generally, the aromatic protons present in a molecule appear in the region between 6.8 to $8.5 \mathrm{ppm}$ with various spin multiplicities depends on the nature of the protons and environments. In the ${ }^{1} \mathrm{H}$ NMR spectrum of the molecule 1, the signals resulted in the region between 7.33 and 7.24 with two one proton integrals as well as a two protons doublet resulted in the region $7.14 \mathrm{ppm}$ with a vicinal coupling constant value $4.8 \mathrm{~Hz}$ are considered to be the protons of aromatic moiety attached to the 4-position of the pyran nucleus. The benzylic proton present at $\mathrm{C}-4$ position o the pyran ring exhibited at $4.39 \mathrm{ppm}$ as a singlet while the two protons of $\mathrm{NH}_{2}$ group resonated at $4.70 \mathrm{ppm}$ as a singlet. The diastereotopic methylene protons (H16) present at the side chain of the $4 H$-pyran derivative 1 appeared as two singlets at 6.05 and $5.60 \mathrm{ppm}$. However, another set of diaseteretopic methylene protons (H11 and H10) appeared as a group with a multiplet between 4.30 and $4.20 \mathrm{ppm}$. Since there are four diastereotopic protons present in the later case and there is no much difference in magnetic environment also, it is quite obvious that the signals appear in close proximity and hence they provide multiplet. The protons of the methyl group which is attached to the olefinic carbon of the side chain (H17) appeared as a singlet at $1.92 \mathrm{ppm}$ while the protons o another methyl group which is attached at the carbon adjacent to the oxygen o the pyran scaffold (H18) resonated as a singlet at $2.38 \mathrm{ppm}$.

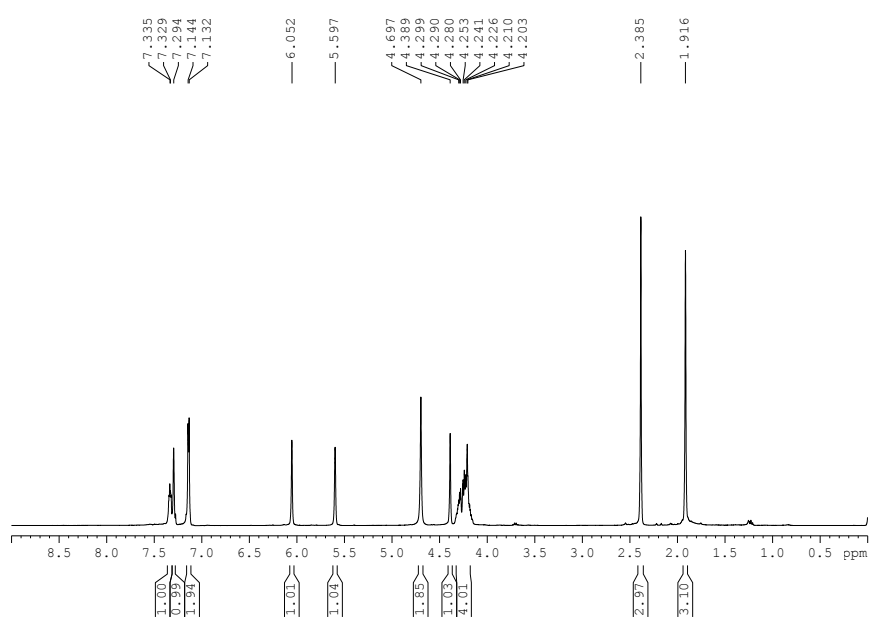

Fig. $2{ }^{1} \mathrm{H}$ NMR spectrum of $4 H$-pyran derivative 1

\section{J. ${ }^{13} \mathrm{C}$ NMR analysis of $4 \mathrm{H}$-pyran derivative 1}

The spectrum of ${ }^{13} \mathrm{C}$ NMR of the compound $4 H$-pyran derivative 1 has been put on view in Fig. 3. In the spectrum of ${ }^{13} \mathrm{C}$ NMR of target molecule $\mathbf{1}$, the ester carbonyl group attached to the carbon of pyran nucleus and the other ester carbonyl functionality adjacent to the carbon of olefin unit occurred in the down filed region 165.3 and $167.0 \mathrm{ppm}$, respectively. The pyran ring carbons $\mathrm{C} 2$ and $\mathrm{C} 6$ observed at 157.7 and 158.2 ppm, respectively while the carbons C3 and C5 resonated at 107.0 and $62.4 \mathrm{ppm}$, respectively. The ipso carbon of the phenyl group attached to the pyran ring resonated at 146.1 ppm and bromo substituted ipso carbon exhibited its resonance at $135.8 \mathrm{ppm}$. The carbons of aromatic moiety (four) are resonated in the region $130.5 \sim 122.8 \mathrm{ppm}(130.4,130.3,130.1$ and 122.8). The carbon of terminal olefin C16 is resonated at $126.3 \mathrm{ppm}$, while $\mathrm{C} 15$ (quaternary carbon) is located at $135.7 \mathrm{ppm}$. The signal at $118.6 \mathrm{ppm}$ is because of carbon of nitrile moiety $(\mathrm{C} \equiv \mathrm{N})$ at C5. C10 and C11, the methylenic carbon, exhibited signals at 62.2 and $61.5 \mathrm{ppm}$, respectively while the benzylic carbon (C4) emerged at $38.6 \mathrm{ppm}$. The carbons of methyl moieties, C17 and C18 observed in the upfield area at 18.3 and $18.7 \mathrm{ppm}$, respectively.

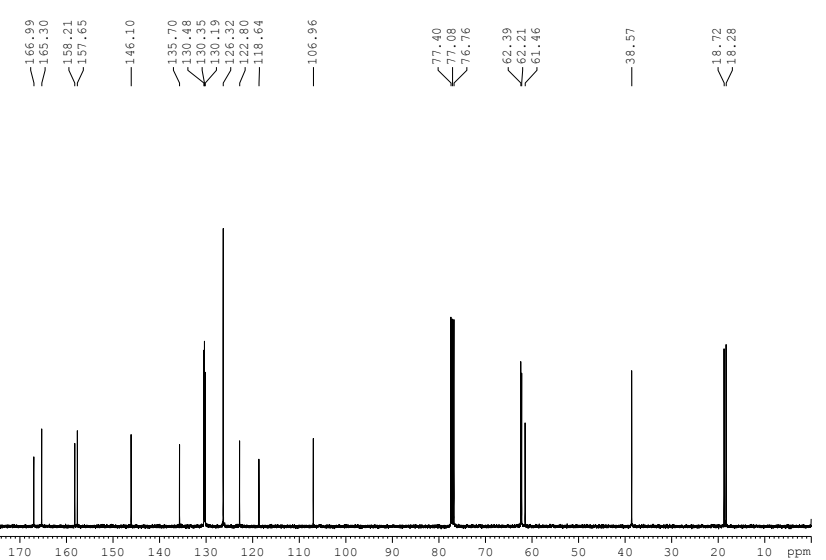

Fig. $3{ }^{13} \mathrm{C}$ NMR spectrum of $4 H$-pyran derivative 1 


\section{Novel Pyran Derivative Ornamented with free Amino and Nitrile Functionalities: Synthesis and Spectroscopic Characterization}

K. C. 3. HSQC and HMBC analysis of $4 \mathrm{H}$-pyran derivative 1

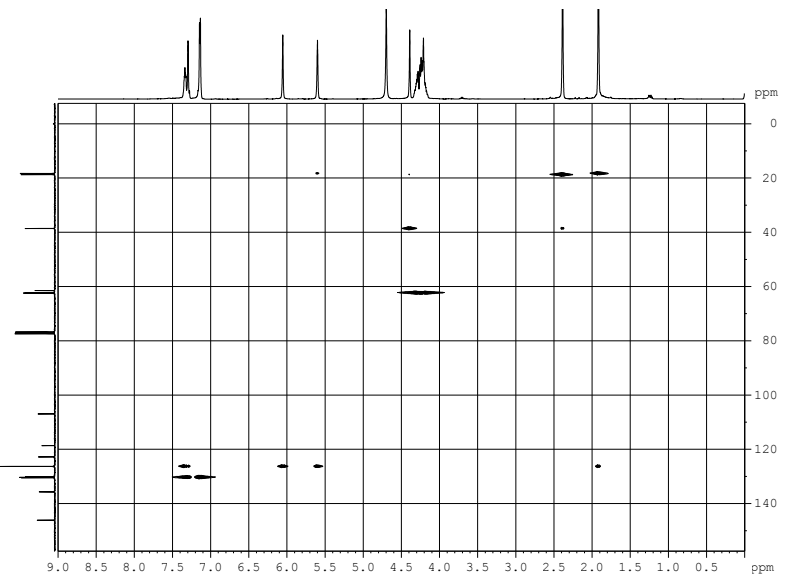

Fig. 4 HSQC spectrum of $4 H$-pyran derivative 1

In the ${ }^{1} \mathrm{H}^{13} \mathrm{C}$ COSY spectrum, as shown in Fig. 4, the carbon signal at $38.6 \mathrm{ppm}$ shows HSQC correlation with benzylic proton at $\mathrm{C}-4$, hence it is assigned to $-\mathrm{CH}$ at $\mathrm{C}-4$. The correlation peaks at $62.4,107.0,118.6,146.1$ and $157.7 \mathrm{ppm}$ in its HMBC spectrum (Fig. 5) further confirms the same.

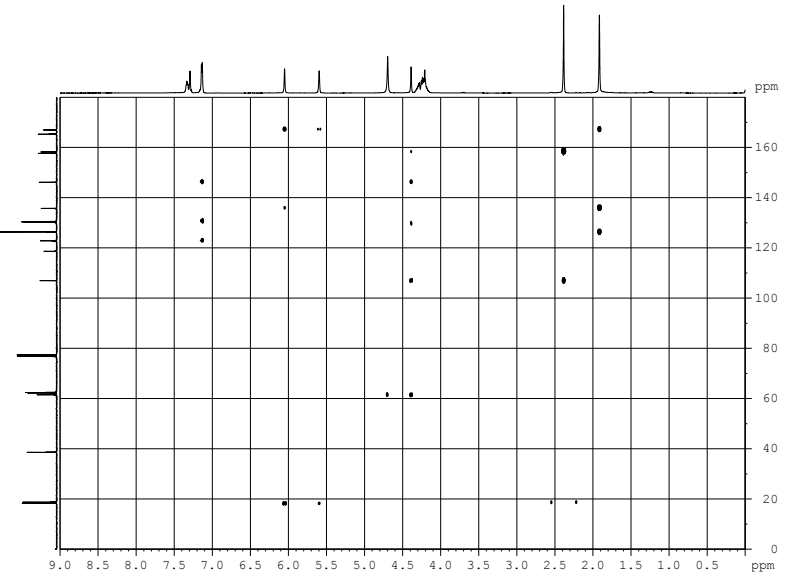

Fig. 5 HMBC spectrum of $\mathbf{4 H}$-pyran derivative 1

The peak at $146.1 \mathrm{ppm}$ is because of ipso carbon (C22) of the phenyl motif based on its HMBC correlation with H-4 proton and aromatic protons. The signals of aromatic carbons resonated in the region 122.8-135.7 ppm which is further confirmed by their correlation spectra.

Table 2. HMBC and HSQC correlations of $4 H$-pyran derivatives 1

\begin{tabular}{|c|c|c|}
\hline Signals & $\begin{array}{l}\text { Correlations } \\
\text { in HSQC }\end{array}$ & Correlations in $\mathrm{HMBC}$ \\
\hline $\begin{array}{l}(4.39) \\
\text { (Benzylic } \\
\text { proton) }\end{array}$ & 38.6 & $\begin{array}{l}62.4(\alpha), 107.0(\alpha), 118.6 \\
(\beta), 146.1(\alpha), 157.7(\gamma)\end{array}$ \\
\hline $\begin{array}{l}\text { C16 (6.05, } \\
5.60)\end{array}$ & 126.3 & $\begin{array}{l}135.7(\alpha), 167.0(\beta), 18.7 \\
(\beta) .\end{array}$ \\
\hline C17 (1.92) & 18.3 & $\begin{array}{l}135.7(\alpha), 167.0(\beta), 126.3 \\
(\beta) .\end{array}$ \\
\hline C18 (2.39) & 18.7 & $157.7(\alpha), 107.0(\beta)$ \\
\hline
\end{tabular}

A group of signals appeared as multiplet between 4.30 and $4.20 \mathrm{ppm}$ exhibits cross peaks with the signals of carbons at 62.2 and $61.5 \mathrm{ppm}$, suggests the carbon signals are because of $\mathrm{C}-10$ and $\mathrm{C}-11$. The couple of singlets at 2.39 and $1.92 \mathrm{ppm}$ show cross peaks with the signals of carbons at 18.7 and 18.3 ppm, which imply that the signals of carbons are because of C-18 and C-17, respectively. Over all, the peaks in the spectra of ${ }^{1} \mathrm{H}$ and ${ }^{13} \mathrm{C}$ NMR are unequivocally assigned by using HSQC spectral analysis. All the correlations of HSQC and HMBC are furnished in Table 2.

\section{CONCLUSION}

We have reported synthesis of an interesting novel 4H-pyran derivative tethered with free amino and nitrile groups (1) by adopting a multicomponent reaction. This reaction proceeds in water, an environmentally green solvent and the duration of the reaction is also shorter. The complete structure of the molecule is unambiguously established based on one dimensional and two-dimensional spectroscopic techniques. Synthesis of a diverse range of this class of molecules besides the preliminary biological activities of the target molecule 1 is under progress.

\section{ACKNOWLEDGMENT}

Financial assistance provided by the Indian Council of Medical Research, New Delhi (No.58/16/2013BMS), Kalasalingam Academy of Research and Education, Anand nagar, India (PDF to $\mathrm{CU}$ and $\mathrm{KG}$ ) is gratefully acknowledged.

\section{REFERENCES}

[1] E. Ruijter, R. V. A. Orru, "Multicomponent reactions - opportunities for the pharmaceutical industry," Drug Discovery Today: Technologies, vol. 10, pp. 15-20, 2013.

[2] M. C. Pirrung, K. D. Sarma, "Multicomponent Reactions Are Accelerated in Water," J. Am. Chem. Soc., vol. 126, pp. 444-445, Dec 2003.

[3] Y. Hayashi, "Pot economy and one-pot synthesis," Chem. Sci., vol. 7, pp 866-880, Jan 2016.

[4] M. K. Ghorai, R. Talukdar, D. P. Tiwari, "An efficient synthetic route to carbocyclic enaminonitriles via Lewis acid catalysed domino-ring-opening-cyclisation (DROC) of donor-acceptor cyclopropanes with malononitrile," Chem. Commun., vol. 49 (2013) pp. 8205-8207, Jul 2013.

[5] S. Nagaraju, K. Sathish, B. Paplal, D. Kashinath, ““'On-water” catalyst-free, one-pot synthesis of quaternary centered and spiro-tetrahydrothiophene-barbiturate hybrids," Tetrahedron Lett. vol. 58 (2017) pp. 2865-2871, Jul 2017.

[6] S. Huang, Y. Pan, Y. Zhu, A. Wu, "A novel three-component one-pot reaction involving alkynes, urea or thiourea, and aldehydes," Org Lett., vol. 7, pp. 3797-3799, Jul 2005.

[7] D. Srikrishna, P. K. Dubey, "PEG-600 mediated one-pot reaction of 3-acetyl-2H-chromen-2-one with heterylthiols and phenylthioureas using tetrabutylammonium tribromide as an efficient green reagent," New J. Chem., vol. 41 (2017) pp.5168-5175, May 2017.

[8] G. Dupeyre, P.Lemoine, N. Ainseba, S. Michel, X. Cachet, "A one-pot synthesis of 7-phenylindolo [3, 2-a] carbazoles from indoles and $\beta$-nitrostyrenes, via an unprecedented reaction sequence," Org. Biomol. Chem., vol. 9, pp. 7780-7790, Aug 2011.

[9] C. Ramalingan, Y. W. Kwak, Tetrachlorosilane catalyzed multicomponent one-step fusion of biopertinent pyrimidine heterocycles," Tetrahedron, vol. 64, pp. 5023-5031, May 2008.

[10] C. Ramalingan, S. J. Park, I. S. Lee, Y. W. Kwak, “A piperidinium triflate catalyzed Biginelli reaction," Tetrahedron, vol. 66 , pp. 2987-2994, April 2010. 
[11] M. Zangouei, A. A. Esmaeili, J. T. Mague, "One-pot three component isocyanide-based reaction: Synthesis of novel tetracyclic fused furo [2', 3': 4, 5] pyrimido [2, 1-b][1, 3] benzothiazole," Tetrahedron, vol. 73, pp. 2894-2900, May 2017.

[12] S. W. Youn, E. M. Lee, "Metal-Free One-Pot Synthesis of N,N'-Diarylamidines and N-Arylbenzimidazoles from Arenediazonium Salts, Nitriles, and Free Anilines," Org. Lett., vol. 18 pp. 5728-5731, Oct 2016.

[13] D. O. Moon, K. C. Kim, C. Y. Jin, M. H Han, C. Park, K. J. Lee, Y. M. Park, Y. H. Choi, G. Y. Kim, "Inhibitory effects of eicosapentaenoic acid on lipopolysaccharide-induced activation in BV2 microglia," Int. Immunopharmacol., vol. 7, pp. 222-229, Feb 2007.

[14] T. Raj, R. K. Bhatia, A. Kapur, M. Sharma, A. K. Saxena, M. P. S. Ishar, "Cytotoxic activity of 3-(5-phenyl-3H-[1, 2, 4] dithiazol-3-yl) chromen-4-ones and 4-oxo-4H-chromene-3-carbothioic acid N-phenylamides,” Eur. J. Med. Chem., vol. 45, pp. 790-794, Feb 2010

[15] Y. Peng, G. Song, "Amino-functionalized ionic liquid as catalytically active solvent for microwave-assisted synthesis of 4H-pyrans," Catal. Commun., vol. 8, pp. 111-114, Feb 2007.

[16] J. L. Wang, D. Liu, Z. J. Zhang, S. Shan, X. Han, S. M. Srinivasula, C. M. Croce, E. S. Alnemri, Z. Huang, "Structure-based discovery of an organic compound that binds Bcl-2 protein and induces apoptosis of tumor cells," PNAS USA., vol. 97, pp. 7124-29, Jun 2000.

[17] J. Y. C. Wu, W. F. Fong, J. X. Zhang, C. H. Leung, H. L. Kwong, M. S. Yang, D. Li, H. Y. Cheung, "Reversal of multidrug resistance in cancer cells by pyranocoumarins isolated from Radix Peucedani," Eur. J. Pharmacol., vol. 473, pp. 9-17 Jul 2003.

[18] M. T. Flavin, J. D. Rizzo, A. Khilevich, A. Kucherenko, A. K. Sheinkman, V. Vilaychack, L. Lin, W. Chen, E. M. Greenwood, T. Pengsuparp, J. M. Pezzuto, S. H. Hughes, T. M. Flavin, M. Cibulski, W. A. Boulanger, R. L. Shone, Z. Q. Xu, "Synthesis, Chromatographic Resolution, and Anti-Human Immunodeficiency Virus Activity of (士)-Calanolide A and Its Enantiomers," J. Med. Chem., vol. 39, pp. 1303-1313, Mar 1996

[19] L. R. Morgan, B. S. Jursic, C. L. Hooper, D. M. Neumann, K. Thangaraj, B. Leblance, "Anticancer activity for 4,4'-Dihydroxybenzophenone-2,4-dinitrophenylhydrazone (A-007) analogues and Their abilities to interact with lymphoendothelial cell surface markers," Bioorg. Med. Chem. Lett., vol. 12, pp. 3407-3411, Dec 2002.

[20] Y. Essamlali, O. Amadine, H. Maati, K. Abdelouahdi, A. Fihri, M. Zahouily, R. S. Varma, A. Solhy, "Highly Efficient One-Pot Three-Component Synthesis of Naphthopyran Derivatives in Water Catalyzed by Phosphates," ACS Sustainable Chem. Eng., vol. 1, pp. 1154-1159, Jun 2013.

[21] T. Akbarzadeh, A. Rafinejad, J. M. Mollaghasem, M. Safari, A. F. Tafti, M. Pordeli, S. K. Ardestani, A. Shafiee, A. Foroumadi, "2-Amino-3-cyano-4-(5-arylisoxazol-3-yl)-4H-chromenes: Synthesis and in vitro cytotoxic activity," Arch. Pharm. Chem. Life Sci., vol. 345, pp. 386-392, Jan 2012.

[22] E. Perez-Sacau, A. Estevez-Braun, A. G. Ravelo, D. G. Yapu, A. G Turba, "Antiplasmodial Activity of Naphthoquinones Related to Lapachol and $\beta$-Lapachone," Chem. Biodiversity, vol. 2, pp. 264-274, Feb 2005.

[23] M. Mahmoodi, A. Aliabadi, S. Emami, M. Safavi, S. Rajabalian, M. Mohagheghi, A. Khoshzaban, A. Samzadeh-Kermani, N. Lamei, A. Shafiee, A. Foroumadi, "Synthesis and in-vitro cytotoxicity of Poly-functionalized 4-(2-arylthiazol-4-yl)-4H-chromenes," Arch. Pharm. Chem. Life Sci., vol. 343, pp. 411-416, Jul 2010.

[24] K. Gong, H. L. Wang, J. Luo, Z. L. Liu, "One-pot synthesis of polyfunctionalized pyrans catalyzed by basic ionic liquid in aqueous media," J. Heterocycl. Chem., vol. 46, pp. 1145-1150, Nov 2009.

[25] S. Abdolmohammadi, S. Balalaie, "Novel and efficient catalysts for the one-pot synthesis of 3,4-dihydropyrano [c] chromene derivatives in aqueous media," Tetrahedron Lett., vol. 48, pp. 3299-3303, Apr 2007.

[26] G. Socrates, "Infrared and Raman Characteristic Group Wave Numbers - Tables and Charts," 3 Ed, John Wiley and sons, New York, 2001.

[27] V. Arjunan, S. Thirunarayanan, S. Mohan, "Energy profile, spectroscopic (FT-IR, FT-Raman and FT-NMR) and DFT studies of 4-bromoisophthalic acid," J. Mol. Struct., vol. 1157, pp. 132-148, Apr 2018.

\section{AUTHORS PROFILE}

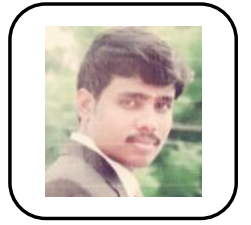

Dr. Chandran Udhaya Kumar Graduated from Thyagaraja College, Madurai (2009) and pursued doctoral research in Organic Chemistry at Annamalai University (2014). He then served as postdoctoral fellow at Kalasalingam Academy of Research and Education, Krishnankoil, India (2015-2018). He published 24 research articles in peer-reviewed journals. His areas of research are Organic Synthesis, X-ray crystallography and Computational Chemistry.

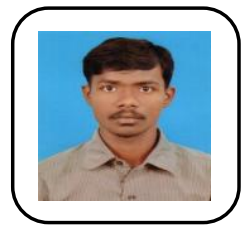

Ramar Sivaramakarthikeyan earned his BSc degree in Chemistry from VHNSN College, Virudhunagar, affiliated to Madurai Kamaraj University, Tamilnadu, India in 2013. He completed his MSc in Chemistry in 2015 from Kalasalingam Academy of Research and Education, Krishnankoil. Currently he is pursuing $\mathrm{PhD}$ at Kalasalingam Academy of Research and Education, Krishnankoil. He has been working in the area of biopertinent heterocycles.

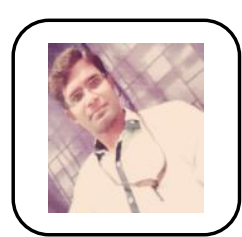

Dr. Kannan Gokula Krishnan Graduated from Sacred Heart College, Thiruppathur (2009) and completed his doctoral degree in Organic Chemistry at Annamalai University (2015). He then prosecuted his postdoctoral research at Kalasalingam Academy of Research and Education, Krishnankoil, India (2015-2018). He published 10 research articles in peer-reviewed journals. His areas of research are Organic Synthesis, development of biopertinent molecules and Computational Chemistry.

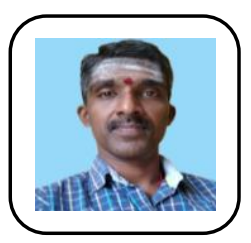

Dr. Muthiah Pillai Velayutham Pillai had his graduation from Christian College, Nagercoil (1997) and earned his doctoral degree from Annamalai University (2014). Presently, he is serving as Assistant Professor of Chemistry at Kalasalingam Academy of Research and Education, Krishnankoil, India. His areas of research are Organic Synthesis, Crystallography ad Computational Chemistry. He published 14 research articles in peer-reviewed journals.

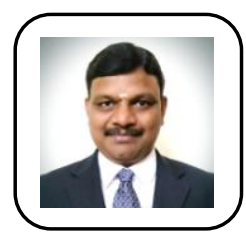

Dr. Chennan Ramalingan is serving as Professor of Chemistry at KARE. He received his $\mathrm{PhD}$ in Organic Chemistry from Annamalai University (2002). After he served as Research Professor at Kyungpook National University, South Korea followed by Assistant Professor at Osaka University, Japan (8 years), he joined at Kalasalingam Academy of Research and Education, Krishnankoil (2011). His research interests include organic synthesis, medicinal chemistry and material chemistry. He published more than 70 International research articles. 